Article

\title{
KRAS and BRAF Mutations as Prognostic and Predictive Biomarkers for Standard Chemotherapy Response in Metastatic Colorectal Cancer: A Single Institutional Study
}

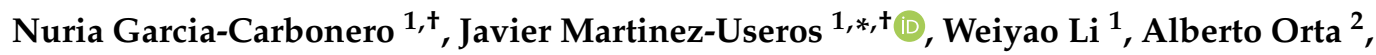 \\ Nuria Perez ${ }^{3}$, Cristina Carames ${ }^{2}\left(\mathbb{D}\right.$, Tatiana Hernandez ${ }^{4}$, Irene Moreno ${ }^{5}$, Gloria Serrano ${ }^{6}$ and \\ Jesus Garcia-Foncillas ${ }^{1,2,4, *}$ \\ 1 Translational Oncology Division, OncoHealth Institute, Fundacion Jimenez Diaz University Hospital, \\ Av. Reyes Católicos 2, 28040 Madrid, Spain; nuria.garciac@quironsalud.es (N.G.-C.); \\ weiyao.li@quironsalud.es (W.L.) \\ 2 Oncology Department, OncoHealth Institute, Fundacion Jimenez Diaz University Hospital, Av. Reyes \\ Católicos 2, 28040 Madrid, Spain; alberto.orta@quironsalud.es (A.O.); ccarames@fjd.es (C.G.) \\ 3 Pathology Department, Fundacion Jimenez Diaz University Hospital, Av. Reyes Católicos 2, 28040 Madrid, \\ Spain; nperez@fjd.es \\ 4 START Madrid-FJD, Hospital Universitario Fundación Jiménez Díaz, Av. de los Reyes Católicos, 2, \\ 28040 Madrid, Spain; tatiana.hg@fjd.es \\ 5 START Madrid-Hospital HM Sanchinarro, Calle de Oña, 10, 28050 Madrid, Spain; \\ imorenocandilejo@gmail.com \\ 6 Oncology Department, University Hospital Infanta Leonor, Avenida de la Gran Vía del Este, 80, \\ 28031 Madrid; Spain; gloriamaria.serrano@salud.madrid.com \\ * Correspondence: javier.museros@oncohealth.eu (J.M.-U.); jesus.garciafoncillas@oncohealth.eu (J.G.-F.); \\ Tel.: +34-915-50-48-00 (J.M.-U. \& J.G.-F.) \\ + These authors contributed equally to this work.
}

Received: 12 December 2019; Accepted: 11 January 2020; Published: 15 January 2020

\begin{abstract}
KRAS mutation is a confirmed predictive biomarker for anti-EGFR monoclonal antibody therapy response for metastatic colorectal cancer. However, its prognosis impact and the predictive potential for first-line standard chemotherapy remains unclear. On the other hand, V600E mutation is the most frequent and studied mutation in the BRAF gene, and it has been associated with a poor outcome of patients and a low response to anti-EGFR treatment. Thus, the aim of this study is to evaluate the role of $K R A S$ and $B R A F$ mutations as prognosis factors and predictive biomarkers for 1st line standard chemotherapy in metastatic colorectal cancer. KRAS mutations and BRAF V600E mutations exhibited a poor outcome ( $p=0.021$ and $p<0.0001$, respectively). Cox multivariate analysis showed that the presence of liver metastasis (HR $=1.595 ; 95 \%$ CI: 1.086-2.343; $p=0.017$ ), KRAS mutation $(\mathrm{HR}=1.643 ; 95 \% \mathrm{CI}: 1.110-2.431 ; p=0.013)$ and $B R A F \mathrm{~V} 600 \mathrm{E}$ mutation $(\mathrm{HR}=5.861 ; 95 \%$ CI: 2.531-13.570; $p<0.0001)$ were statistically significant co-variables for progression-free survival. Interestingly, patients with KRAS mutations were associated with a poor response to first line standard chemotherapy $(p=0.008)$. In contrast, the BRAF V600E mutation did not have any impact on the first line standard chemotherapy response $(p=0.540)$. Therefore, in the present study, we provide new insight on the role of KRAS and $B R A F$, not only as prognosis biomarkers, but also as first line standard chemotherapy response biomarkers in metastatic colorectal cancer.
\end{abstract}

Keywords: KRAS; BRAF; metastatic colorectal cancer; prognosis; chemotherapy; anti-EGFR; biomarker 


\section{Introduction}

Colorectal cancer (CRC) is the third most common tumor diagnosed worldwide [1]. The death rate of CRC has dropped by $53 \%$ since 1970 , primarily due to new advances in early diagnosis and treatment strategies. The 5-year overall survival has increased by $7.9 \%$ in patients aged $65-74$ years [2]. Nevertheless, it still constitutes the third leading cause of cancer-related death in the United States [1]. Despite the improvement in CRC diagnosis and treatment, approximately $35 \%$ of CRC patients show stage IV or metastatic disease (mCRC) at diagnosis, and $20-50 \%$ of stage II and III patients will progress to metastatic disease [3]. The most common sites of distant metastases in mCRC are liver (50-60\%), lymph nodes (35-40\%), lung (10-30\%) and peritoneum (5-20\%) [4]. Thus, the 5-year survival rate for metastatic disease is around $10-20 \%$; however, it has reached $33 \%$ to $50 \%$ with conversion therapy $[5,6]$, which implies an increase in overall survival benefit from 12 months to 30 months over the last 20 years [7].

First-line standard treatment for mCRC patients is still a challenging issue for oncologists. Recommendations include different combinations of drugs, and doublet chemotherapeutic regimens are considered the best standard of care for mCRC. First-line chemotherapy options include fluoropyrimidine-based agents plus leucovorin and oxaliplatin (FOLFOX), or irinotecan (FOLFIRI) or capecitabine plus oxaliplatin [8].

About $60-80 \%$ of CRC shows EGFR overexpression. This fact allows the use of biologic treatments based on monoclonal antibodies (mAbs) against this receptor, which block ligand binding and inhibit the MAPK signaling pathway [9]. KRAS mutations negatively predict response to these inhibitors [10], and anti-VEGFR (vascular endothelial growth factor) therapies are recommended in the presence of these mutations [11]. The combination of standard chemotherapy and biologic treatment has significantly improved the outcome of $\mathrm{mCRC}$ patients in first- and second-line treatment [12,13]. Therefore, testing KRAS status is recommended in routine clinical practice for better patient management [14]. BRAF V600E mutation also appears to predict the lack of benefit from anti-EGFR mAbs, and it has also been considered a biomarker of poor prognosis and resistance to standard therapies [15-17]. Unfortunately, $\mathrm{mCRC}$ patients treated with these antibodies progress and develop resistance in most cases [18]. If the disease progresses, one should administer different cytotoxic drugs in order to avoid chemotherapy resistance $[19,20]$.

KRAS is a factor that belongs to the GTPase RAS superfamily and triggers crucial signaling cascades, such as the RAF-MEK-ERK (MAPK) kinase cascade or PIK3CA-AKT-mTOR axis. These pathways are involved in cell growth, proliferation, differentiation or survival, and they perform a key role in tumorigenesis when they are aberrantly activated [21]. For these reasons, KRAS is considered one of the most important players in human cancers. Activating mutations in KRAS have been described in $90 \%$ of pancreatic tumors, $35 \%$ of lung cancers and $30-50 \%$ of CRCs [22]. KRAS mutations are found in codons 12 or 13 of exon 2 in the $90 \%$ of CRCs, especially in the phosphate-binding loop of the protein. It has been suggested that mutations at codon 12 are involved in local invasion and metastasis, whereas mutations at codon 13 could be more related to adenoma-carcinoma transition [23]. As activating KRAS mutations are major events that drive tumorigenesis in many types of tumors, it is currently one of the most important targets for drug development.

On the other hand, $B R A F$ encodes a cytoplasmic serine-threonine kinase that acts immediately downstream of KRAS in the MAPK signaling pathway. Its aberrant activation enhances cell proliferation and survival and it is critical for tumorigenesis in many types of tumors [24]. Over $90 \%$ of activating $B R A F$ mutations in CRC are due to a change in the nucleotide 1799 of the exon 15, which causes a thymine to adenine change, leading to a substitution of valine by glutamate. This mutation is known as BRAF V600E mutation [25], and has been found in 100\% of hairy cell leukaemias [26], in approximately $50 \%$ of melanomas [27], in $50 \%$ of papillary thyroid cancers $[28,29]$ or in $1-3 \%$ of non-small cell lung carcinomas [30,31]. In mCRC the incidence of $B R A F$ mutations is less than $10 \%$ [15,32]; however, $B R A F$ V600E mutation is considered a relevant therapeutic target for mCRC management. It has been described that KRAS and BRAF mutations are mutually exclusive in CRC, as though they are 
functionally redundant or incompatible, and cells with both mutations are erased [33,34]. Nevertheless, a recent study has described concomitant KRAS and BRAF mutations in CRC [35].

The role of KRAS and BRAF mutations in CRC survival and response to standard chemotherapy regimens is still controversial. Some studies support their potential application as prognosis biomarkers in CRC management [36-38], whereas other studies are not conclusive [39,40]. Regarding standard chemotherapy response, their potential use as predictive biomarkers is not well-established. Some articles have suggested a potential role of these mutations in standard chemotherapy response [41,42], while others have refused it $[17,43]$. Recently, a novel role of tumor location in the outcome of patients has been described. A more favourable outcome in left tumors than right tumors in wild-type KRAS CRC patients has been described [44,45].

As there is a lack of consensus in the scientific community about the role of KRAS and BRAF mutations as prognosis and predictive biomarkers for standard chemotherapy response, in this study we evaluated these mutations in a cohort of 561 patients with $\mathrm{mCRC}$ to provide new insights in regards to this.

\section{Materials and Methods}

\subsection{Patients}

A total of 792 patients with metastasic colorectal cancer who were diagnosed between 1984 and 2012 at the Oncology Department of the Fundacion Jimenez Diaz Hospital were assessed for eligibility. Mutational status from 217 patients could not be determined, and clinical and pathological data from 14 patients were not available; then, a total of 561 patients were included in the study. Among them, 308 patients presented progression-free survival (PFS) information, and 278 patients had complete clinical information on their chemotherapy response (Figure 1). Patients received standard chemotherapy according to standard oncology guidelines, and treatment response was evaluated following the RECIST criteria.

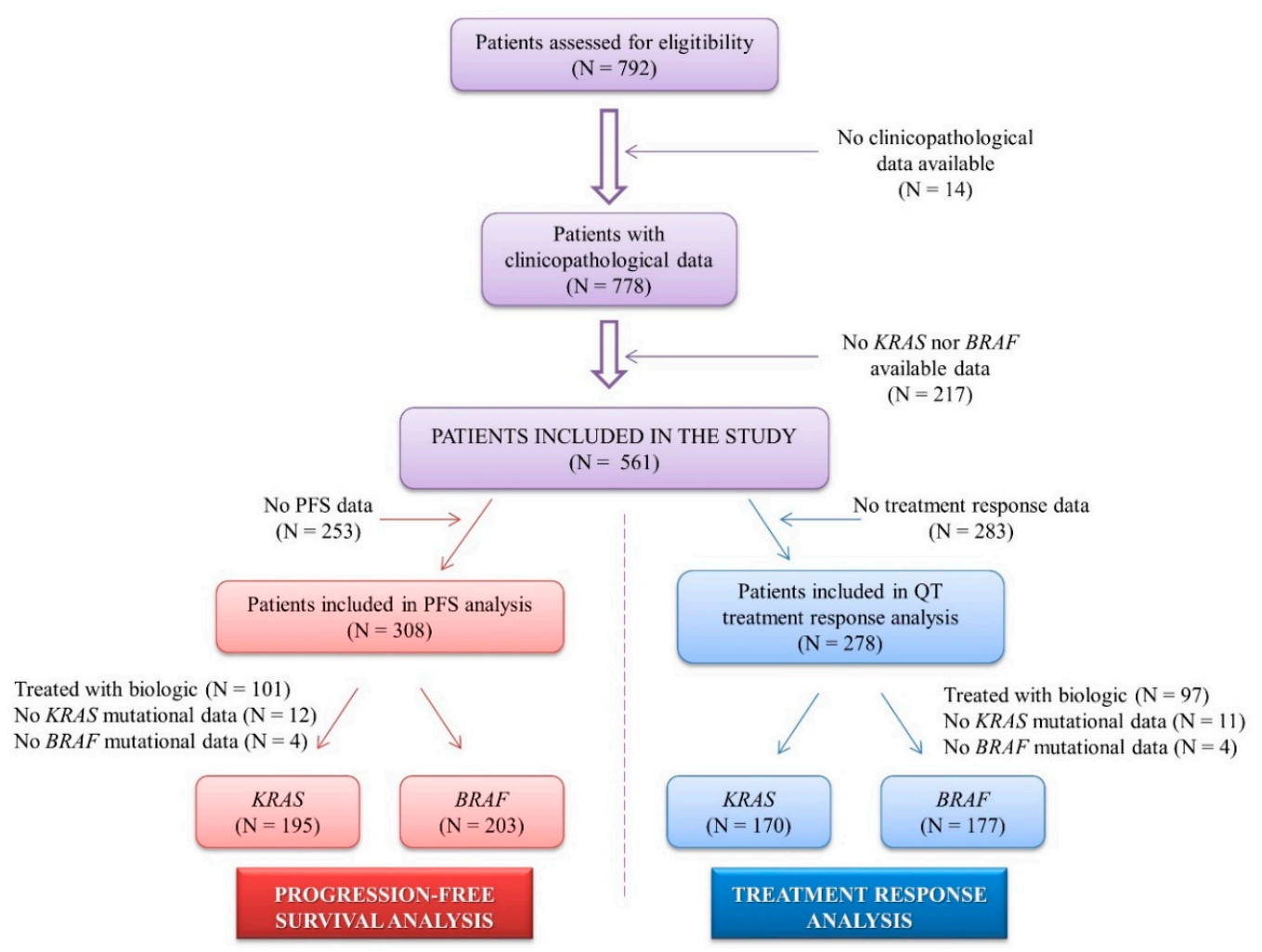

Figure 1. Flow chart presenting the number of patients in progression-free survival and chemotherapy response analyses performed in the study. N: number of patients. 


\subsection{Mutational Analysis}

KRAS and BRAF mutational status was performed in the Pathology Department of Fundacion Jimenez Diaz Hospital. For this, DNA was extracted with a DNA Sample Preparation Kit (Roche Diagnostics, Mannheim, Germany) according to the manufacturer's instructions. KRAS mutational status of each sample was determined by Real-Time PCR with a cobas ${ }^{\circledR}$ KRAS Mutation Test (Roche Diagnostics). BRAF V600E mutation testing was performed by cobas ${ }^{\circledR} B R A F$ mutation test IVD (Roche Diagnostics).

\subsection{Statistical Analysis}

KRAS and BRAF mutational status were used as categorical variables. KRAS mutations in codons 12,13 or 61 were considered as a positive KRAS mutation. BRAF mutational status was analysed as the presence or absence of a V600E mutation. Patients that achieved complete response (CR) or partial response (PR) were categorized as responders, whereas those that exhibited stable disease (SD) or progression on disease (PD) were considered non-responders. Progression-free survival was defined as the time between the dates of diagnosis and recurrence or last follow-up.

The association between KRAS mutations or BRAF V600E mutation with clinicopathological features of patients and treatment response was analysed with Chi-square test or two-tailed Fisher's exact test. We performed survival curves for KRAS or BRAF mutations with Kaplan Meier, and statistical analysis was assessed with the log-rank test. The Cox univariate proportional hazards model was used to compare progression-free survival hazard ratios and $95 \%$ confidence intervals of $B R A F$ and KRAS mutations with other clinical and pathological characteristics. Cox multivariate analysis was performed with those statistically significant covariates obtained from univariate analysis. $p \leq 0.05$ was considered statistically significant. Statistical analysis was performed with the IBM SPSS program, version 20.0 .

\subsection{Ethics Statement}

Clinical samples used in the study were kindly supplied from the BioBank of the Fundacion Jimenez Diaz-Universidad Autonoma de Madrid (PT13/0010/0012 and RD09/0076/00101). This study has been evaluated by the Ethical Review Board of the Health Research Institute of Fundacion Jimenez Diaz (act number 17/14). All patients gave written informed consent for the use of their biological samples for research purposes. Moreover, fundamental ethical principles promoted by Spain (LOPD 15/1999) and the European Union Fundamental Rights of the EU (2000/C364/01) were followed. In addition, all patients' data were processed according to the Declaration of Helsinki (last revision 2013) and Spanish National Biomedical Research Law (14/2007, of 3 July).

\section{Results}

\subsection{Patients Characteristics}

From our institutional cohort of $792 \mathrm{mCRC}$ patients, a total of $561 \mathrm{mCRC}$ patients with available data of KRAS mutations and/or BRAF V600E mutations were included in the study. The median age of patients was 68 years (range 24-93 years) and most patients were male (60.1\%). Among the overall population, 395 patients $(70.4 \%)$ had primary tumor localization in the descending colon (left colon, sigma or rectum), whereas $158(28.2 \%)$ were localized in the ascending colon (cecum, right colon or transverse colon). Of them, 323 patients (57.6\%) presented with synchronous metastasis. Tumors cells were differentiation grade I (well-differentiated) in $15.3 \%$ of cases, $67.9 \%$ were grade II (moderately differentiated), and $9.5 \%$ grade III (poorly differentiated). Performance status (ECOG) was $\geq 2$ in $23.9 \%$ of cases. Regarding metastatic foci, 153 patients (27.3\%) showed metastasis in more than one site, while 394 of patients $(70.2 \%)$ exhibited metastasis in only one site. Liver metastases were found in most of the patients $(66.8 \%)$, followed by lung metastases (33.3\%), or peritoneal metastases $(24.2 \%)$. Furthermore, $24.4 \%$ of patients had lymph node involvement. In our study, we found that KRAS and 
$B R A F$ mutations were mutually exclusive. Mutations in KRAS codons $12 / 13$ were found in $46.2 \%$ of patients, whereas mutations in codon 61 were only detected in $3.4 \%$ of the cases. BRAF was mutated in $6.1 \%$ of patients. The overview of the clinico-pathological features of our institutional cohort of patients is given in Table 1.

Table 1. Clinico-pathological characteristics of CRC patients from our institutional set included in the study.

\begin{tabular}{|c|c|c|c|}
\hline Characteristics & $\mathbf{N}(\%)$ & Characteristics & $\mathbf{N}(\%)$ \\
\hline Median age (range) & 68 years $(24-93)$ & 1st line treatment response & \\
\hline Gender & & CR or PR & $94(16.8 \%)$ \\
\hline Female & $224(39.9 \%)$ & SD or PD & $186(33.2 \%)$ \\
\hline Male & $337(60.1 \%)$ & N/A & $281(50.0 \%)$ \\
\hline Localization of primary tumor & & Number of metastatic sites & \\
\hline Right colon & $158(28.2 \%)$ & 1 & $394(70.2 \%)$ \\
\hline Left colon & $395(70.4 \%)$ & $>1$ & $153(27.3 \%)$ \\
\hline N/A & $8(1.4 \%)$ & N/A & $14(2.5 \%)$ \\
\hline Metastatic pattern & & Liver metastasis & \\
\hline Metachronous & $237(42.2 \%)$ & No & $185(33.0 \%)$ \\
\hline Synchronous & $323(57.6 \%)$ & Yes & $375(66.8 \%)$ \\
\hline N/A & $1(0.2 \%)$ & N/A & $1(0.2 \%)$ \\
\hline Differentiation grade & & Lung metastasis & \\
\hline G1 & $86(15.3 \%)$ & No & $372(66.3 \%)$ \\
\hline G2 & $381(67.9 \%)$ & Yes & $187(33.3 \%)$ \\
\hline G3 & $53(9.5 \%)$ & N/A & $2(0.4 \%)$ \\
\hline $\mathrm{N} / \mathrm{A}$ & $41(7.3 \%)$ & Lymph nodes metastasis & \\
\hline ECOG & & No & $423(75.4 \%)$ \\
\hline 0 & $167(29.8 \%)$ & Yes & $137(24.4 \%)$ \\
\hline 1 & $248(44.2 \%)$ & N/A & $1(0.2 \%)$ \\
\hline 2 & $88(15.7 \%)$ & Peritoneal metastasis & \\
\hline 3 & $46(8.2 \%)$ & No & $424(75.6 \%)$ \\
\hline N/A & $12(2.1 \%)$ & Yes & $136(24.2 \%)$ \\
\hline Metastatic 1st backbone & & N/A & $1(0.2 \%)$ \\
\hline Oxaliplatin-based & $163(29.1 \%)$ & KRAS mutational status & \\
\hline Irinotecan-based & $74(13.2 \%)$ & Wild-type & $254(45.3 \%)$ \\
\hline Fluoropyrimidines & $70(12.5 \%)$ & Mutated in $12 / 13$ & $259(46.2 \%)$ \\
\hline Other & $12(2.1 \%)$ & Mutated in 61 & $19(3.4 \%)$ \\
\hline None & $242(43.1 \%)$ & $\mathrm{N} / \mathrm{A}$ & $29(5.1 \%)$ \\
\hline Metastatic 1st biologic & & $B R A F$ mutational status & \\
\hline None & $458(81.6 \%)$ & Wild-type & $519(92.5 \%)$ \\
\hline Cetuximab & $39(7.0 \%)$ & V600E Mutated & $34(6.1 \%)$ \\
\hline Bevacizumab & $64(11.4 \%)$ & N/A & $8(1.4 \%)$ \\
\hline
\end{tabular}

N: number of patients; CR: complete response; PR: partial response; SD: stable disease; PD: progressive disease; ECOG: Eastern Cooperative Oncology Group performance status scale; N/A: not available.

Then, we aimed to verify whether KRAS or BRAF mutational status was associated with any of the clinical and pathological characteristics of the patients. In this study, the ECOG number was the only variable that was statistically associated with KRAS mutations $(p=0.005)$. BRAF V600E mutation presented a significant association with primary tumor located on the right colon $(p<0.0001)$, with synchronic disease $(p=0.019)$, and with peritoneal metastasis $(p=0.002)$, and showed a high trend towards significance with moderately and poorly differentiated tumors (differentiation grades 2 and 3 , $p=0.098$ ) (Table 2). These results suggest a potential implication of KRAS and BRAF mutations in the tumorigenesis of $\mathrm{mCRC}$. 
Table 2. Statistical association between KRAS and BRAF mutational status with clinico-pathological features of the patients.

\begin{tabular}{|c|c|c|c|c|c|c|}
\hline $\begin{array}{c}\text { Clinico-Pathological } \\
\text { Feature }\end{array}$ & $\begin{array}{c}\text { KRAS } \\
\mathrm{Wt}\end{array}$ & $\begin{array}{c}\text { KRAS } \\
\text { Mut }\end{array}$ & $p$-Value & $\begin{array}{c}\text { BRAF } \\
\text { Wt }\end{array}$ & $\begin{array}{c}\text { BRAF } \\
\text { Mut }\end{array}$ & $p$-Value \\
\hline Age (median, range) & $67.0(27-93)$ & $69.0(24-90)$ & & $68.5(24-93)$ & $63.5(33-85)$ & \\
\hline Gender & & & 0.123 & & & 0.610 \\
\hline Male & $161(63 \%)$ & 158 (57\%) & & $313(60 \%)$ & $19(56 \%)$ & \\
\hline Female & $93(37 \%)$ & $120(43 \%)$ & & $206(40 \%)$ & $15(44 \%)$ & \\
\hline Tumor location & & & 0.179 & & & 0.000 \\
\hline Right colon & $65(26 \%)$ & $84(31 \%)$ & & $130(25 \%)$ & $27(79 \%)$ & \\
\hline Left colon & $188(74 \%)$ & $187(69 \%)$ & & $381(75 \%)$ & $7(21 \%)$ & \\
\hline Metastatic disease & & & 0.763 & & & 0.019 \\
\hline Metachronous & $104(41 \%)$ & $117(42 \%)$ & & $228(44 \%)$ & $8(24 \%)$ & \\
\hline Synchronous & $150(59 \%)$ & $160(58 \%)$ & & $290(56 \%)$ & $26(76 \%)$ & \\
\hline Grade & & & 0.113 & & & 0.098 \\
\hline G1 & $31(13 \%)$ & $49(19 \%)$ & & $83(17 \%)$ & $2(7 \%)$ & \\
\hline $\mathrm{G} 2+\mathrm{G} 3$ & $199(87 \%)$ & $212(81 \%)$ & & $400(83 \%)$ & $28(93 \%)$ & \\
\hline ECOG & & & 0.005 & & & 0.771 \\
\hline $0 / 1$ & $205(82 \%)$ & $193(71 \%)$ & & $384(76 \%)$ & $25(74 \%)$ & \\
\hline $2 / 3$ & $45(18 \%)$ & $77(29 \%)$ & & $123(24 \%)$ & $9(26 \%)$ & \\
\hline Liver metastasis & & & 0.105 & & & 0.161 \\
\hline No & $91(36 \%)$ & $81(29 \%)$ & & $168(32 \%)$ & $15(44 \%)$ & \\
\hline Yes & $163(64 \%)$ & $196(71 \%)$ & & $350(68 \%)$ & $19(56 \%)$ & \\
\hline Lung metastasis & & & 0.400 & & & 0.200 \\
\hline No & $171(68 \%)$ & $179(64 \%)$ & & $340(66 \%)$ & $26(76 \%)$ & \\
\hline Yes & $81(32 \%)$ & $99(36 \%)$ & & $177(34 \%)$ & $8(24 \%)$ & \\
\hline Lymph nodes metastasis & & & 0.897 & & & 0.054 \\
\hline No & $194(76 \%)$ & $210(76 \%)$ & & $396(76 \%)$ & $21(62 \%)$ & \\
\hline Yes & $60(24 \%)$ & $67(24 \%)$ & & $122(24 \%)$ & $13(38 \%)$ & \\
\hline Peritoneal metastasis & & & 0.446 & & & 0.002 \\
\hline No & $190(75 \%)$ & $215(78 \%)$ & & $399(77 \%)$ & $18(53 \%)$ & \\
\hline Yes & $64(25 \%)$ & $62(22 \%)$ & & $119(23 \%)$ & $16(47 \%)$ & \\
\hline Number of metastatic sites & & & 0.564 & & & 0.483 \\
\hline 1 & $180(73 \%)$ & $192(71 \%)$ & & $366(72 \%)$ & $22(67 \%)$ & \\
\hline$>1$ & $67(27 \%)$ & $80(29 \%)$ & & $140(28 \%)$ & $11(33 \%)$ & \\
\hline
\end{tabular}

N: number of patients; ECOG: Eastern Cooperative Oncology Group as performance status scale; wt: wild-type; mut: mutated.

\subsection{Patients That Received Biologic Treatment Showed a Better Outcome and Treatment Response}

It is widely known that biologic treatment improves survival of patients; therefore, we assessed this association. In this study, cetuximab (anti-EGFR mAB) or bevacizumab (anti-VEGFR mAb) were administered to mCRC patients as biologic treatments depending on the KRAS mutational status of tumors. We confirmed that patients that received standard chemotherapy alone showed a worse outcome ( $p=0.028$ ) than those who received chemotherapy plus biologic treatment (Figure S1). Furthermore, the ratio of recurrence was higher in patients who did not receive biologic treatment $(73 \%)$ compared to combination therapy $(55 \%)(p=0.002)$ (Table S1). The predictive role of KRAS and $B R A F$ mutations in biologic therapies response is well understood and applied by oncologist worldwide in the clinical management of $\mathrm{mCRC}$. For this reason, we focused on the association between $K R A S$ and $B R A F$ mutations and standard chemotherapy response in order to elucidate not only the prognosis potential of KRAS and BRAFV600E mutations but also their predictive role for standard chemotherapy response. 


\subsection{KRAS and BRAF Mutations Have An Impact on Progression-Free Survival of Patients}

KRAS and BRAF mutational status was available in 195 and 203 cases, respectively, of the total number of patients who did not receive biologic treatment. KRASBRAFKRAS mutations were detected in $103 / 195$ patients (53\%). KRAS mutations were significantly associated with progression-free survival $(p=0.021)$ (Figure 2A). The median PFS was 28 months (95\% CI: 22.206-33.794 months) for KRAS wild-type patients while patients with KRAS mutations has a PFS of 19 months (95\% CI: 15.678-22.322 months). Concerning BRAF analysis, we found a mutation in BRAF in only 11 cases (5\%). Despite the scarce number of patients with this alteration, BRAFV600E mutation was associated with PFS $(p<0.0001$; Figure $2 B$ ). Here, patients with $B R A F$ wild-type presented with longer median progression-free survival (median $=24$ months, 95\% CI: 18.678-29.322 months) in comparison to BRAF mutated patients (median $=9$ months, $95 \%$ CI: 5.167-12.833 months). Therefore, these results confirm the implication of KRAS and $B R A F$ mutations on patient prognosis.

A

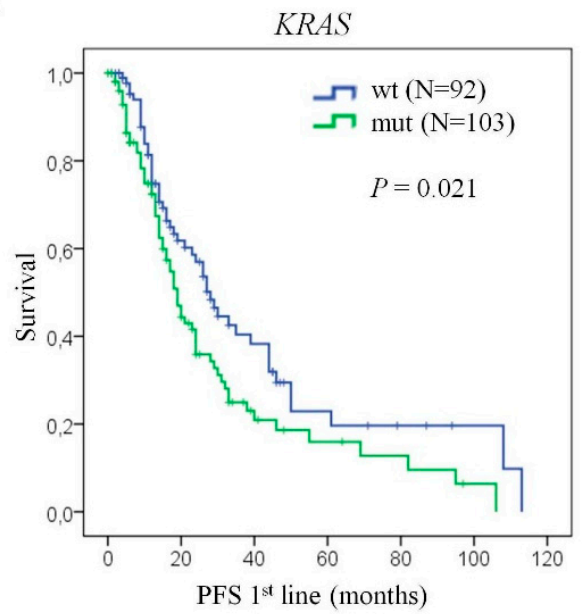

B

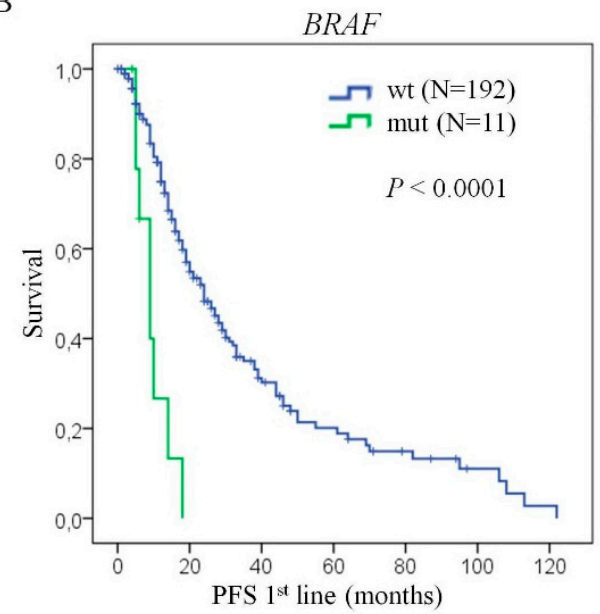

Figure 2. KRAS or BRAF mutations confer poor prognosis to mCRC patients. Kaplan Meier curves of progression-free survival of mCRC patients, (A) with KRAS mutations versus KRAS wild-type, and (B) with $B R A F V 600$ E mutations versus $B R A F$ wild-type. Statistical analysis performed with log-rank test. $\mathrm{N}$ : number of patients; PFS: progression-free survival; wt: wild-type; mut: mutated; $P$ : $p$-Value.

Cox proportional hazards model for progression-free survival was performed to compare the prognostic potential of KRAS and BRAFV600E mutational status with the other clinico-pathological characteristics included in the study. Here, the univariate analysis revealed that patients with mutations in KRAS present higher risk of recurrence than wild-type patients (HR $=1.529,95 \% \mathrm{CI}: 1.058-2.211$, $p=0.024)$. Moreover, $B R A F$ mutated patients also showed higher risk of progression than $B R A F$ wild-type $(\mathrm{HR}=4.288,95 \% \mathrm{CI}: 2.033-9.046, p<0.0001)$. We have also found a statistically significant association between PFS and the presence of liver metastasis (HR = 1.691,95\%CI: 1.177-2.432, $p=0.005$ ). Interestingly, after multivariate analysis, these three factors remained statistically significant, not only $B R A F(\mathrm{HR}=5.861,95 \% \mathrm{CI}: 2.531-13.570, p<0.0001)$, but also KRAS (HR = 1.643, 95\%CI: 1.110-2.431, $p=0.013)$ and liver metastasis ( $\mathrm{HR}=1.595,95 \% \mathrm{CI}: 1.086-2.343, p=0.017)$ (Table 3). These results confirm the prognostic value of $K R A S$ and $B R A F V 600 \mathrm{E}$ mutations for the adequate management of $\mathrm{mCRC}$ patients in routine clinical practice. 
Table 3. Uni- and multivariate proportional hazard model of $K R A S$ and $B R A F$, and other clinico-pathological variables in the progression-free survival of mCRC patients.

\begin{tabular}{|c|c|c|c|c|}
\hline & \multicolumn{4}{|c|}{ Univariate PFS $(95 \% \mathrm{CI})$} \\
\hline & HR & Lower & Upper & $p$-Value \\
\hline Age (<vs. $>68$ years $)$ & 1.137 & 0.802 & 1.612 & 0.470 \\
\hline Gender (Female vs. Male) & 1.166 & 0.820 & 1.659 & 0.393 \\
\hline Localization (Right colon vs. Left colon) & 1.245 & 0.840 & 1.844 & 0.275 \\
\hline Grade & & & & 0.757 \\
\hline G1 & 1.000 & & & \\
\hline G2 & 0.859 & 0.311 & 2.370 & 0.769 \\
\hline G3 & 1.056 & 0.428 & 2.603 & 0.906 \\
\hline ECOG (0/1 vs. $2 / 3)$ & 1.331 & 0.775 & 2.284 & 0.300 \\
\hline Metastatic 1st backbone & & & & 0.301 \\
\hline Oxaliplatin-based & 1.000 & & & \\
\hline Irinotecan-based & 0.914 & 0.615 & 1.360 & 0.659 \\
\hline Fluoropyrimidines & 1.295 & 0.818 & 2.051 & 0.269 \\
\hline Liver metastasis (No vs. Yes) & 1.691 & 1.177 & 2.432 & 0.005 \\
\hline Lung metastasis (No vs. Yes) & 1.320 & 0.924 & 1.887 & 0.128 \\
\hline Lymph nodes metastasis (No vs. Yes) & 1.178 & 0.809 & 1.716 & 0.393 \\
\hline Peritoneal metastasis (No vs. Yes) & 1.333 & 0.892 & 1.991 & 0.161 \\
\hline Number of metastasis sites ( 1 vs. $>1$ ) & 1.387 & 0.931 & 2.067 & 0.108 \\
\hline KRAS mutation (No vs. Yes) & 1.529 & 1.058 & 2.211 & 0.024 \\
\hline \multirow[t]{2}{*}{$B R A F$ mutation (No vs. Yes) } & 4.288 & 2.033 & 9.046 & 0.000 \\
\hline & \multicolumn{4}{|c|}{ Multivariate PFS (95\% CI) } \\
\hline Liver metastasis (No vs. Yes) & 1.595 & 1.086 & 2.343 & 0.017 \\
\hline KRAS mutation (No vs. Yes) & 1.643 & 1.110 & 2.431 & 0.013 \\
\hline BRAF mutation (No vs. Yes) & 5.861 & 2.531 & 13.570 & 0.000 \\
\hline
\end{tabular}

PFS: progression-free survival; HR: hazard ratio; CI: confidence interval; vs: versus; ECOG: Eastern Cooperative Oncology Group performance status scale.

\subsection{KRAS Mutation Status is Associated with a Lack of Benefit From Standard Chemotherapy}

In regards to treatment regimens, a total of $278 \mathrm{mCRC}$ patients were treated with standard chemotherapy as first line therapy. Among them, 97 patients were excluded from the study as they received biologic treatment regimens based on anti-EGFR or anti-VEGFR monoclonal antibodies. As a result, a total number of 170 patients with KRAS mutational status and 177 patients with BRAF mutational status were included in the study to assess the association between standard chemotherapy response and KRAS or BRAF mutation status (Figure 1). Among the KRAS mutated subgroup, 75/93 $(81 \%)$ patients presented with stable disease or progression to standard chemotherapy compared to $48 / 93(62 \%)$ patients with KRAS wild-type. Furthermore, only $19 \%$ of patients with a KRAS mutation achieved complete or partial response to treatment, while double the number of patients with KRAS wild-type $(38 \%)$ showed complete or partial response $(p=0.008)$ (Table 4$)$. In contrast, BRAF mutation did not show a clear association with treatment response, where $73 \%$ of patients with $B R A F$ wild-type presented with disease recurrence compared to $78 \%$ of the BRAF mutated subgroup $(p=0.540)$ (Table 4$)$. Overall, these results support the role of KRAS mutational status as a predictive biomarker not only for biologic treatment but also for standard chemotherapy response.

Table 4. Statistical association between $K R A S$ and $B R A F$ mutational status and treatment response to standard chemotherapy.

\begin{tabular}{lccc}
\hline & CR + PR & SD + PD & $p$-Value \\
\hline KRAS wild-type & $29(38 \%)$ & $48(62 \%)$ & \\
KRAS mutated & $18(19 \%)$ & $75(81 \%)$ & \\
\hline \multicolumn{4}{c}{} \\
\hline BRAF wild-type & $46(27 \%)$ & $122(73 \%)$ & 0.008 \\
BRAF mutated & $2(22 \%)$ & $7(78 \%)$ & \\
\hline
\end{tabular}

CR: complete response; PR: partial response; SD: stable disease; PD: progressive disease. 


\section{Discussion}

Personalized medicine is based on the premise that patients can be stratified into subgroups according to predictive biomarkers in order to be treated with target therapies [46]. The use of monoclonal antibodies against EGFR or VEGFR in the management of mCRC has represented a substantial improvement in the outcome of these patients [47]. As a result, most mCRC patients nowadays receive biologic treatment as first-line therapy. In this study, we have observed in our cohort of patients that the combination of biologic therapy plus standard chemotherapeutic agents presents a benefit both in outcome of patients and treatment response compared to the use of standard chemotherapy alone, which goes in accordance with previous studies.

$K R A S$ and $B R A F$ mutation status is broadly used in the routine clinical practice for the diagnosis and treatment management in the field of CRC. KRAS mutation is considered a key point for treatment decisions in oncology as it can predict resistance to monoclonal antibodies against epidermal growth factor receptor (EGFR) [48], restricting the use of these therapies to KRAS wild-type CRC patients [10]. $B R A F$ mutations also confer resistance to anti-EGFR therapies in patients with mCRC [49,50]. Biologic treatment is predominantly administered in combination with standard chemotherapy to mCRC patients. The current selection of standard chemotherapeutic treatment strategies is mostly based on the patients characteristics and the clinical, pathological and molecular features of tumors [51,52]. As there are not useful predictive biomarkers to select chemotherapeutic strategies for $\mathrm{mCRC}$, it is necessary to identify new molecular markers to predict standard chemotherapy response.

Several studies have tried to elucidate the role of KRAS and BRAF mutations in cytotoxic drugs response, but the impact of the mutational status on the effectiveness of standard chemotherapy remains unclear. Furthermore, most of these studies include a low number of patients, which limits their statistical power. Lin et al. suggested KRAS mutation as a predictor of oxaliplatin sensitivity in vitro by downregulation of ERCC1 [53]. Indeed, a benefit of oxaliplatin-based chemotherapy for KRAS mutated mCRC patients has been reported [41]. A recent study suggests that patients with mutations in KRAS codon 12 present a significant survival advantage compared to wild-type patients treated with irinotecan-based therapy [54]. However, other studies reported that mutation status of KRAS did not impact on irinotecan or oxaliplatin response $[17,55]$. Other studies reported a lack of benefit from chemotherapy for those KRAS mutated mCRC patients $[43,56]$. Cui et al. reported in a meta-analysis that patients with $B R A F$ mutations showed worse objective response rates than wild-type patients treated with standard chemotherapy [42]. Other studies suggested that the predictive role of $B R A F$ mutations is not significant in standard chemotherapy response [17,57]. Therefore, there is an absence of evidence to conclude that KRAS or BRAF mutated patients are less likely to obtain a benefit from standard chemotherapeutic strategies.

In our study, we provide new insight on the role of KRAS and BRAF mutations, focused on the prediction of response to adjuvant standard chemotherapy alone based mainly on oxaliplatin, irinotecan and fluoropyrimidines. Moreover, the fact that all patients have been treated at a single institution makes this study highly homogeneous. Here, we have observed that KRAS mutations can predict resistance to standard chemotherapy $(p=0.008)$. Thus, patients showed stable disease or relapse in $81 \%(\mathrm{~N}=75)$ of cases with KRAS mutation, compared to $62 \%(\mathrm{~N}=48)$ of KRAS wild-type patients. Unfortunately, we could not stratify our cohort of patients regarding the specific chemotherapeutic agents used because of the low number of cases in some of the subgroups.

The use of biologic treatment could influence the prognosis impact of KRAS and $B R A F$ mutations in the outcome of patients. Indeed, the role of KRAS as a prognostic biomarker in CRC is still rather controversial. KRAS mutations have been associated with a worse prognosis in several reports [58-61]. However, there are other several articles that have failed to show a role of KRAS mutations in the outcome of patients [62-65]. For this reason, we aimed to analyse the prognostic potential of KRAS and $B R A F$ mutations in a subset of patients that did not receive biologic therapy along the study period and only received standard chemotherapy as first-line treatment. 
Here, we provide evidence on the impact of KRAS mutations on the time to progression of patients. Nevertheless, it would be interesting to analyse the role of the specific mutations in the KRAS gene. For instance, Jones et al. found that different mutations in KRAS codon 12 have different impacts on survival, especially G12C and G12V, which remained significant among the five most common mutations [58]. The poorer prognosis role of these specific mutations in KRAS was in codon 12, which was confirmed recently by different authors [66,67]. Mutations in codon 146 are also found in mCRC patients but at a low frequency [68,69]. Nevertheless, their role in mCRC prognosis and treatment response is still unknown due to the limited statistical power of these analyses, and large-scale trials are needed [70]. The role of KRAS mutation status in other types of tumors has also been studied, e.g., $K R A S$ mutation is a poor prognostic factor and erlotinib or gefitinib resistance biomarker in non-small cell lung cancer [71,72].

The BRAF mutation was also significantly associated with poor outcome in our cohort of patients. Indeed, Cox proportional hazards model confirmed the association between shorter progression-free survival and KRAS mutation, BRAF mutation and the presence of liver metastasis than other clinicopathological variables. This worst prognosis impact is consistent with previous publications about mCRC [37,73-75]. Furthermore, the BRAF V600E mutation has also been associated with a reduced survival in other types of tumors like melanoma [76] or papillary thyroid cancer [77].

In addition, we have found an association between KRAS or BRAF mutation status and the differentiation grade of tumors, which suggests a role of these activating mutations in tumor development and progression. KRAS mutation was also associated with a higher performance status. Interestingly, most patients with a $B R A F$ mutation $(\mathrm{N}=26,76 \%)$ also exhibited synchronic metastatic disease. This observation suggests that BRAF V600E mutation is an early event that contributes to tumorigenesis of mCRC. Indeed, the $B R A F$ mutation was positively associated with the presence of peritoneal metastases $(p=0.002)$, and revealed a high trend towards significance with lymph node affection $(p=0.054)$; however, it is unlikely to be associated with lung metastases $(p=0.200)$. These results go in accordance to those of Tran el al. regarding localization of metastases. These authors reported $46 \%$ vs. $24 \%$ for peritoneal metastasis when comparing BRAF mutated vs. BRAF wild-type respectively, $53 \%$ vs. $38 \%$ for lymph nodes metastases, and $35 \%$ vs. $49 \%$ for lung metastasis [37]. In our cohort, $47 \%$ of BRAF mutated patients showed peritoneal metastases vs. $23 \%$ BRAF wild-type patients, $38 \%$ show lymph nodes metastases vs. $24 \%$, and $24 \%$ vs. $34 \%$ show lung metastases respectively. In both studies, $B R A F$ mutated patients are more likely to present with peritoneal metastases and lymph node affection, and the $B R A F$ mutation does not seem to confer tropism to lungs. It has also been reported that $B R A F$ wild-type tumors are usually localized in the left side of the colon, while $B R A F$ mutations are associated with the right side of the colon [78,79]. In our cohort, $75 \%$ of $B R A F$ wild-type tumors were localised in the left colon, whereas $79 \%$ of $B R A F$ mutated tumors were found predominantly in the right side, which goes in accordance with the literature. Therefore, these results contribute to the understanding of the role of the BRAF mutation in mCRC management, where BRAF is providing new treatment strategies based on molecular targeted therapy [80].

\section{Conclusions}

Most published articles analyse the impact of KRAS and BRAF mutations in mCRC patients that received standard chemotherapy in combination with biologic treatment. Moreover, their prognostic potential is rather controversial. In the present study, we have provided new insights into the roles of $K R A S$ and $B R A F$ mutations, and we propose their use as prognostic and predictive biomarkers for standard chemotherapy response in the $\mathrm{MCRC}$ scenario.

Supplementary Materials: The following are available online at http://www.mdpi.com/2073-4409/9/1/219/s1, Figure S1: Patient treated with biologic therapy presented longer progression-free survival, Table S1: Treatment response of patients that received standard chemotherapeutic alone vs. standard chemotherapy plus biologic treatment. 
Author Contributions: Conceptualization: N.G.-C., J.M.-U. and J.G.-F.; methodology: N.P.; formal analysis: N.G.-C.; investigation: J.M.-U., W.L., N.G.-C.; CRC patients data base: C.C., T.H., I.M. and G.S.; data curation: J.M.-U., N.G.-C.; writing—original draft preparation: J.M.-U., N.G.-C.; review and editing: A.O.; visualization: N.G.-C; supervision: J.M.-U. and J.G.-F.; project administration: J.M.-U.; funding acquisition: J.G.-F. All authors have read and agreed to the published version of the manuscript.

Funding: This research was funded by the RNA-Reg Consolider-Consortium (CSD2009-00080), and by Spanish Health Research Project Funds (PI16/01468) from Instituto de Salud Carlos III-FEDER (J.G.-F.), both of the Spanish Ministry of Economy, Industry, and Competitiveness.

Acknowledgments: We thank Oliver Shaw (FIIS-FJD) for editing the manuscript for English usage, clarity, and style.

Conflicts of Interest: The authors declare no conflict of interest.

\section{References}

1. Siegel, R.L.; Miller, K.D.; Jemal, A. Cancer statistics, 2019. CA Cancer J. Clin. 2019, 69, 7-34. [CrossRef] [PubMed]

2. Van Abbema, D.; Vissers, P.; de Vos-Geelen, J.; Lemmens, V.; Janssen-Heijnen, M.; Tjan-Heijnen, V. Trends in Overall Survival and Treatment Patterns in Two Large Population-Based Cohorts of Patients with Breast and Colorectal Cancer. Cancers 2019, 11, 1239. [CrossRef] [PubMed]

3. Zacharakis, M.; Xynos, I.D.; Lazaris, A.; Smaro, T.; Kosmas, C.; Dokou, A.; Felekouras, E.; Antoniou, E.; Polyzos, A.; Sarantonis, J.; et al. Predictors of Survival in Stage IV Metastatic Colorectal Cancer. Anticancer Res. 2010, 30, 653-660. [PubMed]

4. Bhullar, D.S.; Barriuso, J.; Mullamitha, S.; Saunders, M.P.; O’Dwyer, S.T.; Aziz, O. Biomarker concordance between primary colorectal cancer and its metastases. EBioMedicine 2019, 40, 363-374. [CrossRef]

5. Hamers, P.; Bos, A.C.R.K.; May, A.M.; Punt, C.J.A.; Koopman, M.; Vink, G.R. Recent changes in overall survival of real-life stage IV colorectal cancer patients. JCO 2019, 37, 3522. [CrossRef]

6. Adam, R.; Kitano, Y. Multidisciplinary approach of liver metastases from colorectal cancer. Ann. Gastroenterol. Surg 2019, 3, 50-56. [CrossRef] [PubMed]

7. Cremolini, C.; Schirripa, M.; Antoniotti, C.; Moretto, R.; Salvatore, L.; Masi, G.; Falcone, A.; Loupakis, F. First-line chemotherapy for mCRC-A review and evidence-based algorithm. Nat. Rev. Clin. Oncol. 2015, 12, 607-619. [CrossRef]

8. Malka, D.; Rotolo, F.; Boige, V. First-line treatment in metastatic colorectal cancer: Important or crucial? Eur. J. Cancer 2017, 84, 363-366. [CrossRef]

9. Porru, M.; Pompili, L.; Caruso, C.; Biroccio, A.; Leonetti, C. Targeting KRAS in metastatic colorectal cancer: Current strategies and emerging opportunities. J. Exp. Clin. Cancer Res. 2018, 37, 57. [CrossRef]

10. Lièvre, A.; Bachet, J.-B.; Le Corre, D.; Boige, V.; Landi, B.; Emile, J.-F.; Côté, J.-F.; Tomasic, G.; Penna, C.; Ducreux, M.; et al. KRAS mutation status is predictive of response to cetuximab therapy in colorectal cancer. Cancer Res. 2006, 66, 3992-3995. [CrossRef]

11. Atreya, C.E.; Yaeger, R.; Chu, E. Systemic Therapy for Metastatic Colorectal Cancer: From Current Standards to Future Molecular Targeted Approaches. Am. Soc. Clin. Oncol. Educ. Book 2017, 37, 246-256. [CrossRef] [PubMed]

12. Bennouna, J.; Sastre, J.; Arnold, D.; Österlund, P.; Greil, R.; Van Cutsem, E.; von Moos, R.; Viéitez, J.M.; Bouché, O.; Borg, C.; et al. Continuation of bevacizumab after first progression in metastatic colorectal cancer (ML18147): A randomised phase 3 trial. Lancet Oncol. 2013, 14, 29-37. [CrossRef]

13. Hurwitz, H.; Fehrenbacher, L.; Novotny, W.; Cartwright, T.; Hainsworth, J.; Heim, W.; Berlin, J.; Baron, A.; Griffing, S.; Holmgren, E.; et al. Bevacizumab plus irinotecan, fluorouracil, and leucovorin for metastatic colorectal cancer. N. Engl. J. Med. 2004, 350, 2335-2342. [CrossRef] [PubMed]

14. Allegra, C.J.; Jessup, J.M.; Somerfield, M.R.; Hamilton, S.R.; Hammond, E.H.; Hayes, D.F.; McAllister, P.K.; Morton, R.F.; Schilsky, R.L. American Society of Clinical Oncology provisional clinical opinion: Testing for KRAS gene mutations in patients with metastatic colorectal carcinoma to predict response to anti-epidermal growth factor receptor monoclonal antibody therapy. J. Clin. Oncol. 2009, 27, 2091-2096. [CrossRef]

15. Tol, J.; Nagtegaal, I.D.; Punt, C.J.A. BRAF mutation in metastatic colorectal cancer. N. Engl. J. Med. 2009, 361, 98-99. [CrossRef] [PubMed] 
16. Di Nicolantonio, F.; Martini, M.; Molinari, F.; Sartore-Bianchi, A.; Arena, S.; Saletti, P.; De Dosso, S.; Mazzucchelli, L.; Frattini, M.; Siena, S.; et al. Wild-type BRAF is required for response to panitumumab or cetuximab in metastatic colorectal cancer. J. Clin. Oncol. 2008, 26, 5705-5712. [CrossRef]

17. Richman, S.D.; Seymour, M.T.; Chambers, P.; Elliott, F.; Daly, C.L.; Meade, A.M.; Taylor, G.; Barrett, J.H.; Quirke, P. KRAS and BRAF mutations in advanced colorectal cancer are associated with poor prognosis but do not preclude benefit from oxaliplatin or irinotecan: Results from the MRC FOCUS trial. J. Clin. Oncol. 2009, 27, 5931-5937. [CrossRef]

18. Pietrantonio, F.; Vernieri, C.; Siravegna, G.; Mennitto, A.; Berenato, R.; Perrone, F.; Gloghini, A.; Tamborini, E.; Lonardi, S.; Morano, F.; et al. Heterogeneity of Acquired Resistance to Anti-EGFR Monoclonal Antibodies in Patients with Metastatic Colorectal Cancer. Clin. Cancer Res. 2017, 23, 2414-2422. [CrossRef]

19. Foo, J.; Michor, F. Evolution of acquired resistance to anti-cancer therapy. J. Theor. Biol. 2014, 355, 10-20. [CrossRef]

20. Chambers, A.E.; Frick, J.; Tanner, N.; Gerkin, R.; Kundranda, M.; Dragovich, T. Chemotherapy re-challenge response rate in metastatic colorectal cancer. J. Gastrointest. Oncol. 2018, 9, 679-686. [CrossRef]

21. Poulogiannis, G.; Luo, F.; Arends, M.J. RAS signalling in the colorectum in health and disease. Cell Commun. Adhes. 2012, 19, 1-9. [CrossRef] [PubMed]

22. Cox, A.D.; Fesik, S.W.; Kimmelman, A.C.; Luo, J.; Der, C.J. Drugging the undruggable RAS: Mission possible? Nat. Rev. Drug Discov. 2014, 13, 828-851. [CrossRef] [PubMed]

23. Guerrero, S.; Casanova, I.; Farré, L.; Mazo, A.; Capellà, G.; Mangues, R. K-ras codon 12 mutation induces higher level of resistance to apoptosis and predisposition to anchorage-independent growth than codon 13 mutation or proto-oncogene overexpression. Cancer Res. 2000, 60, 6750-6756. [PubMed]

24. Davies, H.; Bignell, G.R.; Cox, C.; Stephens, P.; Edkins, S.; Clegg, S.; Teague, J.; Woffendin, H.; Garnett, M.J.; Bottomley, W.; et al. Mutations of the BRAF gene in human cancer. Nature 2002, 417, 949-954. [CrossRef] [PubMed]

25. Korphaisarn, K.; Kopetz, S. BRAF-directed Therapy in Metastatic Colorectal Cancer. Cancer J. 2016, 22, 175-178. [CrossRef]

26. Tiacci, E.; Trifonov, V.; Schiavoni, G.; Holmes, A.; Kern, W.; Martelli, M.P.; Pucciarini, A.; Bigerna, B.; Pacini, R.; Wells, V.A.; et al. BRAF Mutations in Hairy-Cell Leukemia. N. Engl. J. Med. 2011, 364, 2305-2315. [CrossRef]

27. Greaves, W.O.; Verma, S.; Patel, K.P.; Davies, M.A.; Barkoh, B.A.; Galbincea, J.M.; Yao, H.; Lazar, A.J.; Aldape, K.D.; Medeiros, L.J.; et al. Frequency and spectrum of BRAF mutations in a retrospective, single-institution study of 1112 cases of melanoma. J. Mol. Diagn. 2013, 15, 220-226. [CrossRef]

28. Kim, T.H.; Park, Y.J.; Lim, J.A.; Ahn, H.Y.; Lee, E.K.; Lee, Y.J.; Kim, K.W.; Hahn, S.K.; Youn, Y.K.; Kim, K.H.; et al. The association of the BRAF(V600E) mutation with prognostic factors and poor clinical outcome in papillary thyroid cancer: A meta-analysis. Cancer 2012, 118, 1764-1773. [CrossRef] [PubMed]

29. Fukushima, T.; Suzuki, S.; Mashiko, M.; Ohtake, T.; Endo, Y.; Takebayashi, Y.; Sekikawa, K.; Hagiwara, K.; Takenoshita, S. BRAF mutations in papillary carcinomas of the thyroid. Oncogene 2003, 22, 6455-6457. [CrossRef]

30. Brustugun, O.T.; Khattak, A.M.; Trømborg, A.K.; Beigi, M.; Beiske, K.; Lund-Iversen, M.; Helland, Å. BRAF-mutations in non-small cell lung cancer. Lung Cancer 2014, 84, 36-38. [CrossRef] [PubMed]

31. Ding, X.; Zhang, Z.; Jiang, T.; Li, X.; Zhao, C.; Su, B.; Zhou, C. Clinicopathologic characteristics and outcomes of Chinese patients with non-small-cell lung cancer and BRAF mutation. Cancer Med. 2017, 6, 555-562. [CrossRef] [PubMed]

32. Tie, J.; Gibbs, P.; Lipton, L.; Christie, M.; Jorissen, R.N.; Burgess, A.W.; Croxford, M.; Jones, I.; Langland, R.; Kosmider, S.; et al. Optimizing targeted therapeutic development: Analysis of a colorectal cancer patient population with the BRAFV600E mutation. Int. J. Cancer 2011, 128, 2075-2084. [CrossRef] [PubMed]

33. Rajagopalan, H.; Bardelli, A.; Lengauer, C.; Kinzler, K.W.; Vogelstein, B.; Velculescu, V.E. Tumorigenesis: RAF/RAS oncogenes and mismatch-repair status. Nature 2002, 418, 934. [CrossRef] [PubMed]

34. Morkel, M.; Riemer, P.; Bläker, H.; Sers, C. Similar but different: Distinct roles for KRAS and BRAF oncogenes in colorectal cancer development and therapy resistance. Oncotarget 2015, 6, 20785-20800. [CrossRef]

35. Midthun, L.; Shaheen, S.; Deisch, J.; Senthil, M.; Tsai, J.; Hsueh, C.-T. Concomitant KRAS and BRAF mutations in colorectal cancer. J. Gastrointest. Oncol. 2019, 10, 577-581. [CrossRef] 
36. Tanaka, M.; Omura, K.; Watanabe, Y.; Oda, Y.; Nakanishi, I. Prognostic factors of colorectal cancer: K-ras mutation, overexpression of the p53 protein, and cell proliferative activity. J. Surg. Oncol. 1994, 57, 57-64. [CrossRef]

37. Tran, B.; Kopetz, S.; Tie, J.; Gibbs, P.; Jiang, Z.-Q.; Lieu, C.H.; Agarwal, A.; Maru, D.M.; Sieber, O.; Desai, J. Impact of BRAF mutation and microsatellite instability on the pattern of metastatic spread and prognosis in metastatic colorectal cancer. Cancer 2011, 117, 4623-4632. [CrossRef]

38. Ogino, S.; Nosho, K.; Kirkner, G.J.; Kawasaki, T.; Meyerhardt, J.A.; Loda, M.; Giovannucci, E.L.; Fuchs, C.S. CPG island methylator phenotype, microsatellite instability, BRAF mutation and clinical outcome in colon cancer. Gut 2009, 58, 90-96. [CrossRef]

39. Ogino, S.; Meyerhardt, J.A.; Irahara, N.; Niedzwiecki, D.; Hollis, D.; Saltz, L.B.; Mayer, R.J.; Schaefer, P.; Whittom, R.; Hantel, A.; et al. KRAS mutation in stage III colon cancer and clinical outcome following intergroup trial CALGB 89803. Clin. Cancer Res. 2009, 15, 7322-7329. [CrossRef]

40. Chouhan, H.; Sammour, T.; L Thomas, M.; W Moore, J. Prognostic significance of BRAF mutation alone and in combination with microsatellite instability in stage III colon cancer. Asia Pac. J. Clin. Oncol. 2019, 15, 69-74. [CrossRef]

41. Lin, Y.-L.; Liang, Y.-H.; Tsai, J.-H.; Liau, J.-Y.; Liang, J.-T.; Lin, B.-R.; Hung, J.-S.; Lin, L.-I.; Tseng, L.-H.; Chang, Y.-L.; et al. Oxaliplatin-Based Chemotherapy Is More Beneficial in KRAS Mutant than in KRAS Wild-Type Metastatic Colorectal Cancer Patients. PLoS ONE 2014, 9, e86789. [CrossRef] [PubMed]

42. Cui, D.; Cao, D.; Yang, Y.; Qiu, M.; Huang, Y.; Yi, C. Effect of BRAF V600E mutation on tumor response of anti-EGFR monoclonal antibodies for first-line metastatic colorectal cancer treatment: A meta-analysis of randomized studies. Mol. Biol. Rep. 2014, 41, 1291-1298. [CrossRef] [PubMed]

43. Loriot, Y.; Mordant, P.; Deutsch, E.; Olaussen, K.A.; Soria, J.-C. Are RAS mutations predictive markers of resistance to standard chemotherapy? Nat. Rev. Clin. Oncol. 2009, 6, 528-534. [CrossRef] [PubMed]

44. Grassadonia, A.; Di Marino, P.; Ficorella, C.; Cortellini, A.; Cannita, K.; Parisi, A.; Gamucci, T.; Zoratto, F.; Vici, P.; Barba, M.; et al. Impact of primary tumor location in patients with RAS wild-type metastatic colon cancer treated with first-line chemotherapy plus anti-EGFR or anti-VEGF monoclonal antibodies: A retrospective multicenter study. J. Cancer 2019, 10, 5926-5934. [CrossRef]

45. Benavides, M.; Díaz-Rubio, E.; Carrato, A.; Abad, A.; Guillén, C.; Garcia-Alfonso, P.; Gil, S.; Cano, M.T.; Safont, M.J.; Gravalos, C.; et al. Tumour location and efficacy of first-line EGFR inhibitors in KRAS/RAS wild-type metastatic colorectal cancer: Retrospective analyses of two phase II randomised Spanish TTD trials. ESMO Open 2019, 4, e000599. [CrossRef]

46. Jackson, S.E.; Chester, J.D. Personalised cancer medicine. Int. J. Cancer 2015, 137, 262-266. [CrossRef] [PubMed]

47. Van Cutsem, E.; Cervantes, A.; Adam, R.; Sobrero, A.; Van Krieken, J.H.; Aderka, D.; Aranda Aguilar, E.; Bardelli, A.; Benson, A.; Bodoky, G.; et al. ESMO consensus guidelines for the management of patients with metastatic colorectal cancer. Ann. Oncol. 2016, 27, 1386-1422. [CrossRef]

48. Sorich, M.J.; Wiese, M.D.; Rowland, A.; Kichenadasse, G.; McKinnon, R.A.; Karapetis, C.S. Extended RAS mutations and anti-EGFR monoclonal antibody survival benefit in metastatic colorectal cancer: A meta-analysis of randomized, controlled trials. Ann. Oncol. 2015, 26, 13-21. [CrossRef]

49. Van Brummelen, E.M.J.; de Boer, A.; Beijnen, J.H.; Schellens, J.H.M. BRAF Mutations as Predictive Biomarker for Response to Anti-EGFR Monoclonal Antibodies. Oncologist 2017, 22, 864-872. [CrossRef]

50. Pietrantonio, F.; Petrelli, F.; Coinu, A.; Di Bartolomeo, M.; Borgonovo, K.; Maggi, C.; Cabiddu, M.; Iacovelli, R.; Bossi, I.; Lonati, V.; et al. Predictive role of BRAF mutations in patients with advanced colorectal cancer receiving cetuximab and panitumumab: A meta-analysis. Eur. J. Cancer 2015, 51, 587-594. [CrossRef]

51. Rossi, L.; Vakiarou, F.; Zoratto, F.; Bianchi, L.; Papa, A.; Basso, E.; Verrico, M.; Lo Russo, G.; Evangelista, S.; Rinaldi, G.; et al. Factors influencing choice of chemotherapy in metastatic colorectal cancer (mCRC). Cancer Manag. Res. 2013, 5, 377-385. [CrossRef]

52. Stein, A.; Bokemeyer, C. How to select the optimal treatment for first line metastatic colorectal cancer. World J. Gastroenterol. 2014, 20, 899-907. [CrossRef] [PubMed]

53. Lin, Y.-L.; Liau, J.-Y.; Yu, S.-C.; Ou, D.-L.; Lin, L.-I.; Tseng, L.-H.; Chang, Y.-L.; Yeh, K.-H.; Cheng, A.-L. KRAS mutation is a predictor of oxaliplatin sensitivity in colon cancer cells. PLoS ONE 2012, 7, e50701. [CrossRef] 
54. Ergun, Y.; Acikgoz, Y.; Bal, O.; Ucar, G.; Dirikoc, M.; Caliskan Yildirim, E.; Akdeniz, N.; Uncu, D. KRAS codon 12 and 13 mutations may guide the selection of irinotecan or oxaliplatin in first-line treatment of metastatic colorectal cancer. Expert Rev. Mol. Diagn. 2019, 19, 1131-1140. [CrossRef]

55. Cabart, M.; Frénel, J.-S.; Campion, L.; Ramée, J.-F.; Dupuis, O.; Senellart, H.; Hiret, S.; Douillard, J.-Y.; Bennouna, J. KRAS mutation does not influence oxaliplatin or irinotecan efficacy, in association with bevacizumab, in first line treatment of metastatic colorectal cancer]. Bull. Cancer 2016, 103, 541-551. [CrossRef] [PubMed]

56. Nemunaitis, J.; Cox, J.; Meyer, W.; Courtney, A.; Mues, G. Irinotecan hydrochloride (CPT-11) resistance identified by K-ras mutation in patients with progressive colon cancer after treatment with 5-fluorouracil (5-FU). Am. J. Clin. Oncol. 1997, 20, 527-529. [CrossRef] [PubMed]

57. Hutchins, G.; Southward, K.; Handley, K.; Magill, L.; Beaumont, C.; Stahlschmidt, J.; Richman, S.; Chambers, P.; Seymour, M.; Kerr, D.; et al. Value of Mismatch Repair, KRAS, and BRAF Mutations in Predicting Recurrence and Benefits From Chemotherapy in Colorectal Cancer. JCO 2011, 29, 1261-1270. [CrossRef] [PubMed]

58. Jones, R.P.; Sutton, P.A.; Evans, J.P.; Clifford, R.; McAvoy, A.; Lewis, J.; Rousseau, A.; Mountford, R.; McWhirter, D.; Malik, H.Z. Specific mutations in KRAS codon 12 are associated with worse overall survival in patients with advanced and recurrent colorectal cancer. Br. J. Cancer 2017, 116, 923-929. [CrossRef]

59. Lièvre, A.; Bachet, J.-B.; Boige, V.; Cayre, A.; Le Corre, D.; Buc, E.; Ychou, M.; Bouché, O.; Landi, B.; Louvet, C.; et al. KRAS Mutations as an Independent Prognostic Factor in Patients With Advanced Colorectal Cancer Treated With Cetuximab. JCO 2008, 26, 374-379. [CrossRef]

60. Conlin, A.; Smith, G.; Carey, F.A.; Wolf, C.R.; Steele, R.J.C. The prognostic significance of K-ras, p53, and APC mutations in colorectal carcinoma. Gut 2005, 54, 1283-1286. [CrossRef]

61. Kwak, M.S.; Cha, J.M.; Yoon, J.Y.; Jeon, J.W.; Shin, H.P.; Chang, H.J.; Kim, H.K.; Joo, K.R.; Lee, J.I. Prognostic value of KRAS codon 13 gene mutation for overall survival in colorectal cancer. Medicine 2017, 96, 7882. [CrossRef] [PubMed]

62. Rose, J.S.; Serna, D.S.; Martin, L.K.; Li, X.; Weatherby, L.M.; Abdel-Misih, S.; Zhao, W.; Bekaii-Saab, T. Influence of KRAS Mutation Status in Metachronous and Synchronous Metastatic Colorectal Adenocarcinoma. Cancer 2012, 118, 6243-6252. [CrossRef] [PubMed]

63. Won, D.D.; Lee, J.I.; Lee, I.K.; Oh, S.-T.; Jung, E.S.; Lee, S.H. The prognostic significance of KRAS and BRAF mutation status in Korean colorectal cancer patients. BMC Cancer 2017, 17, 403. [CrossRef] [PubMed]

64. Lee, J.-H.; Ahn, J.; Park, W.S.; Choe, E.K.; Kim, E.; Shin, R.; Heo, S.C.; Jung, S.; Kim, K.; Chai, Y.J.; et al. Colorectal Cancer Prognosis Is Not Associated with BRAF and KRAS Mutations-A STROBE Compliant Study. J. Clin. Med. 2019, 8, 111. [CrossRef]

65. Price, T.J.; Hardingham, J.E.; Lee, C.K.; Weickhardt, A.; Townsend, A.R.; Wrin, J.W.; Chua, A.; Shivasami, A.; Cummins, M.M.; Murone, C.; et al. Impact of KRAS and BRAF Gene Mutation Status on Outcomes From the Phase III AGITG MAX Trial of Capecitabine Alone or in Combination With Bevacizumab and Mitomycin in Advanced Colorectal Cancer. J. Clin. Oncol. 2011, 29, 2675-2682. [CrossRef]

66. Hayama, T.; Hashiguchi, Y.; Okamoto, K.; Okada, Y.; Ono, K.; Shimada, R.; Ozawa, T.; Toyoda, T.; Tsuchiya, T.; Iinuma, H.; et al. G12V and G12C mutations in the gene KRAS are associated with a poorer prognosis in primary colorectal cancer. Int. J. Colorectal Dis. 2019, 34, 1491-1496. [CrossRef]

67. Li, W.; Liu, Y.; Cai, S.; Yang, C.; Lin, Z.; Zhou, L.; Liu, L.; Zeng, W. Not all mutations of KRAS predict poor prognosis in patients with colorectal cancer. Int. J. Clin. Exp. Pathol. 2019, 12, 957-967.

68. Loupakis, F.; Ruzzo, A.; Cremolini, C.; Vincenzi, B.; Salvatore, L.; Santini, D.; Masi, G.; Stasi, I.; Canestrari, E.; Rulli, E.; et al. KRAS codon 61, 146 and BRAF mutations predict resistance to cetuximab plus irinotecan in KRAS codon 12 and 13 wild-type metastatic colorectal cancer. Br. J. Cancer 2009, 101, 715-721. [CrossRef]

69. Takahashi, N.; Yamada, Y.; Taniguchi, H.; Akiyoshi, K.; Honma, Y.; Iwasa, S.; Kato, K.; Hamaguchi, T.; Shimada, Y. Mutations in NRAS codon 61, KRAS codon 146, and BRAF V600E as prognostic factors in patients who received anti-EGFR antibody for metastatic colorectal cancer. JCO 2012, 30, e14126. [CrossRef]

70. Imamura, Y.; Lochhead, P.; Yamauchi, M.; Kuchiba, A.; Qian, Z.R.; Liao, X.; Nishihara, R.; Jung, S.; Wu, K.; Nosho, K.; et al. Analyses of clinicopathological, molecular, and prognostic associations of KRAS codon 61 and codon 146 mutations in colorectal cancer: Cohort study and literature review. Mol. Cancer 2014, 13, 135. [CrossRef] 
71. Slebos, R.J.; Kibbelaar, R.E.; Dalesio, O.; Kooistra, A.; Stam, J.; Meijer, C.J.; Wagenaar, S.S.; Vanderschueren, R.G.; van Zandwijk, N.; Mooi, W.J. K-ras oncogene activation as a prognostic marker in adenocarcinoma of the lung. N. Eng. J. Med. 1990, 323, 561-565. [CrossRef] [PubMed]

72. Pao, W.; Wang, T.Y.; Riely, G.J.; Miller, V.A.; Pan, Q.; Ladanyi, M.; Zakowski, M.F.; Heelan, R.T.; Kris, M.G.; Varmus, H.E. KRAS Mutations and Primary Resistance of Lung Adenocarcinomas to Gefitinib or Erlotinib. PLoS Med. 2005, 2, e17. [CrossRef]

73. Tveit, K.M.; Guren, T.; Glimelius, B.; Pfeiffer, P.; Sorbye, H.; Pyrhonen, S.; Sigurdsson, F.; Kure, E.; Ikdahl, T.; Skovlund, E.; et al. Phase III trial of cetuximab with continuous or intermittent fluorouracil, leucovorin, and oxaliplatin (Nordic FLOX) versus FLOX alone in first-line treatment of metastatic colorectal cancer: The NORDIC-VII study. J. Clin. Oncol. 2012, 30, 1755-1762. [CrossRef] [PubMed]

74. Venderbosch, S.; Nagtegaal, I.D.; Maughan, T.S.; Smith, C.G.; Cheadle, J.P.; Fisher, D.; Kaplan, R.; Quirke, P.; Seymour, M.T.; Richman, S.D.; et al. Mismatch repair status and BRAF mutation status in metastatic colorectal cancer patients: A pooled analysis of the CAIRO, CAIRO2, COIN, and FOCUS studies. Clin. Cancer Res. 2014, 20, 5322-5330. [CrossRef] [PubMed]

75. Van Cutsem, E.; Köhne, C.-H.; Láng, I.; Folprecht, G.; Nowacki, M.P.; Cascinu, S.; Shchepotin, I.; Maurel, J.; Cunningham, D.; Tejpar, S.; et al. Cetuximab plus irinotecan, fluorouracil, and leucovorin as first-line treatment for metastatic colorectal cancer: Updated analysis of overall survival according to tumor KRAS and BRAF mutation status. J. Clin. Oncol. 2011, 29, 2011-2019. [CrossRef] [PubMed]

76. Hugdahl, E.; Kalvenes, M.B.; Puntervoll, H.E.; Ladstein, R.G.; Akslen, L.A. BRAF-V600E expression in primary nodular melanoma is associated with aggressive tumour features and reduced survival. Br. J. Cancer 2016, 114, 801-808. [CrossRef]

77. Xing, M.; Alzahrani, A.S.; Carson, K.A.; Shong, Y.K.; Kim, T.Y.; Viola, D.; Elisei, R.; Bendlová, B.; Yip, L.; Mian, C.; et al. Association Between BRAF V600E Mutation and Recurrence of Papillary Thyroid Cancer. J. Clin. Oncol. 2015, 33, 42-50. [CrossRef]

78. Carnerero Córdoba, L.; González Cebrián, I.; Rodríguez González, C.; González-Flores, E.; Conde, V.; Delgado Ureña, M.; Jurado García, J.; González-Astorga, B. Clinical significance of BRAF mutations in colorectal cancer: A retrospective study of one institution in a real-life population. Ann. Oncol. 2019, 30, 389. [CrossRef]

79. Chiu, J.W.; Krzyzanowska, M.K.; Serra, S.; Knox, J.J.; Dhani, N.C.; Mackay, H.; Hedley, D.; Moore, M.; Liu, G.; Burkes, R.L.; et al. Molecular Profiling of Patients With Advanced Colorectal Cancer: Princess Margaret Cancer Centre Experience. Clin. Colorectal Cancer 2018, 17, 73-79. [CrossRef]

80. Van Cutsem, E.; Huijberts, S.; Grothey, A.; Yaeger, R.; Cuyle, P.-J.; Elez, E.; Fakih, M.; Montagut, C.; Peeters, M.; Yoshino, T.; et al. Binimetinib, Encorafenib, and Cetuximab Triplet Therapy for Patients With BRAF V600E-Mutant Metastatic Colorectal Cancer: Safety Lead-In Results From the Phase III BEACON Colorectal Cancer Study. JCO 2019, 37, 1460-1469. [CrossRef] 